\title{
Implant placement with guided bone regeneration in the maxillary aesthetic zone - A case report with 3 years of follow up
}

\author{
Manawar Ahmad $^{1 *}$, Hina Naim ${ }^{1}$, Dhanasekar Balakrishnan ${ }^{2}$, Aparna Narayan ${ }^{2}$ and Abdullah Meshni ${ }^{1}$ \\ ${ }^{1}$ Department of Prosthetic Dental Sciences, College of Dentistry, Jazan University, Saudi Arabia \\ ${ }^{2}$ Department of Prosthodontics, Manipal College of Dental Sciences, Manipal University, India
}

\begin{abstract}
The placement of implants in a prosthetically driven position depends on the quantity and quality of available bone especially in the anterior region of maxilla. Implant placement and its restoration becomes clinically challenging when the alveolar ridge lacks sufficient bone volume. Additional surgical procedures are required to augment the bone deficiency in such clinical situations. Advanced procedures such as guided bone regeneration provides a conducive environment for successful placement of implants, where non-osseous cells are inhibited and osteoblast derived from the periosteum and the bones are induced to form new bone. This article presents a case report of simultaneous approach of guided bone regeneration and implant placement in the maxillary anterior with narrow ridge defect. After six months of healing period implant was aesthetically restored.
\end{abstract}

\section{Introduction}

Dental implants are considered as the first line of treatment in restoring missing teeth now days by most of patients and clinicians. The high predictability and success of osseointegration have led to a shift in the focus towards achieving ideal long-term esthetics with peri-implant bone and tissue architecture. Because prosthetically-driven implant placement is only possible when there is an adequate amount of bone, the presence of resorption can pose a significant clinical challenge. The extraction of teeth can result in up to $50 \%$ loss of alveolar ridge width within the first one to three years. This bone loss is exacerbated if the tooth is removed traumatically or if there are pre-existing endodontic or periodontal pathologies [1,2]. This often requires bone augmentation to create ideal gingival contours and esthetics. A variety of techniques and materials have been used to restore the necessary volume of bony tissue for supporting dental implants. The most commonly described methods in the dental literature are: Guided Bone Regeneration (GBR), onlay veneer grafting, inter-positional inlay grafting, ridge splitting technique and distraction osteogenesis [3-5].

Guided bone regeneration is a frequently used procedure for hard tissue reconstruction. The treatment concept advocates that regeneration of osseous defects is predictably attainable via the application of occlusive membranes, which mechanically exclude non-osteogenic cell populations from the surrounding soft tissues, thereby allowing osteogenic cell populations originating from the parent bone to inhabit the osseous wound. The studies suggest that bone regeneration is significantly enhanced when the invasion of soft tissue into osseous defects is mechanically impeded. There are two approaches in Guided bone regeneration (GBR) - simultaneous and staged approach. In simultaneous approach fixture placement and GBR are performed simultaneously and is indicated only in narrow ridge defects. In staged approach GBR is used to increase the alveolar ridge before fixture placement. This case report presents a simultaneous approach of guided bone regeneration and implant placement in the maxillary anterior with narrow ridge defect [6-9].

\section{Case report}

A thirty five years old female patient reported with a chief complaint of missing anterior teeth and need for aesthetic restoration of the same with fixed prosthesis. She was wearing maxillary anterior removable partial denture from last 10 months. The patient gave the history of extraction due to mobility of upper anterior teeth one year back. Her medical history was non-contributory. Her expectations were reasonable and her psychological profile was good. On transgingival probing the presence of Seibert class II ridge in relation to maxillary anterior 11 was evident. There was a slight buccal defect in the gingiva in the region of tooth \#11 due to normal shrinkage, probably exacerbated by pressure exerted from the removable appliance (Figure 1). The periapical radiograph revealed adequate bone height and mesio-distal bone width. It was explained to the patient that although implants represented an ideal treatment option, it would be necessary to simultaneously augment the bone to allow for optimal bone integration and stability of the implants. The patient agreed to the proposed surgical and prosthetic treatment plan.

A buccal full thickness mucoperiosteal flap was elevated following mid-crestal and intracrevicular incisions on the adjacent teeth. The

Correspondence to: Manawar Ahmad, Assistant Professor, Department of Prosthetic Dental Sciences, College of Dentistry, Jazan University, Saudi Arabia, E-mail: ahmad955mls@gmail.com

Key words: dental implants, guided bone regeneration, ridge augmentation, barrier membrane

Received: February 08, 2017; Accepted: February 23, 2017; Published: February 27,2017 


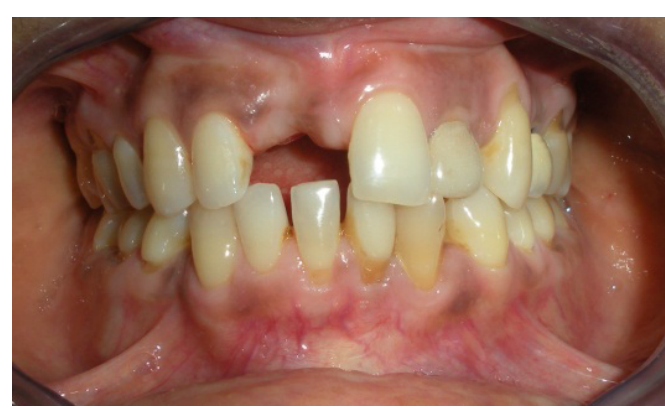

Figure 1. Intra oral view showing buccal defect in \#11 region.

dimension of the ridge was deficient measuring $4.1 \mathrm{~mm}$ in width in the maxillary incisor region. A narrow platform implant $(3.5 \mathrm{~mm} x$ $11.5 \mathrm{~mm}$; Nobel Replace Select Tapered) was placed eqicrestally with an initial torque of $35 \mathrm{~N}$. The primary stability was good but in the midlabial surface of 11 region three threads of the implant was exposed due to deficient ridge (Figure 2). This defect was treated with simultaneous guided bone regeneration using particulate bone graft alloplast (Biooss; Osteohealth Company, NY, USA) [10]. The grafted site was secured with a resorbable membrane (Healiguide, Encoll, Fermont, CA, USA) and tacks (Figures 3 and 4). Undermining of the periosteum to facilitate primary closure with tension free approximation of the flap was completed prior to suturing with 3-0 black silk suture (Ethicon, Johnson \& Johnson Ltd. Aurangabad, India). Patient was advised to clean the surgical area with cotton dipped in $0.2 \%$ chlorhexidine mouth wash twice a day. Patient was called after one week for suture removal. Six months post operatively the maxillary second stage surgery was performed. This period was considered necessary for predictable osseointegration as the site was grafted. The implant head was exposed using a crestal incision and healing abutment was placed. 2 weeks post operatively a well formed gingival cuff was evident (Figure 5). The implant analog was placed and the impression was taken with rubber base impression material. The implant analog was transferred to the impression and the working model was made. Desired modifications were done in the esthetic abutment to achieve good emergence profile (Figure 6), upon which ceramic crown was prepared. The abutment was placed followed by cementation of ceramic crown in the patient's mouth (Figure 7). The patient was given proper supportive periodontal therapy and recalled every three months for one year to evaluate the periodontal status (Figure 8).

\section{Discussion}

Guided Bone Regeneration (GBR) is a technique in which bone growth is enhanced by maintaining the space and preventing soft tissue growth into the area utilizing either a resorbable or non-resorbable barrier membrane and achieving the bone regeneration. It may be performed in conjunction with the placement of the implant or during a surgical intervention prior to implant placement. Various different membrane materials have been used in experimental and clinical studies in the context of GBR treatment. However, before choosing the membrane type, some prerequisites are essential. These include: (1) Biocompatibility, i.e., no interaction between material and tissue, (2) Cell occlusion properties, i.e., to prevent fibrous connective tissue invasion, (3) Integration by the host tissues, (4) Clinical manageability and space making ability [11-13].

Non-resorbable membranes do not undergo the enzymatic degradation when placed in the living body as in the case of the resorbable membranes. Hence, they require a second surgical intervention in order to be removed. Moreover, the exposure of these membranes may lead to total failure of the regeneration process. These disadvantages led to the development of resorbable membrane devices. Absorbable collagen membranes are more frequently in dentistry for guided bone regeneration (GBR). The great advantage of using absorbable membranes is that a second procedure to remove the membrane is not necessary. The membrane is made with a unique manufacturing process which creates a longer resorption profile suited to GBR procedures (six months). The material consists of a fibrillar matrix structure to provide strength for tacking or suturing the membrane if desired. This composition provides excellent handling characteristics when hydrated-thus improving adaptability to various defects [14-16].

This clinical report presentation illustrates restoration of a maxillary anterior partially edentulous ridge with dental implant. Due to the lack of sufficient bone volume to place implant, simultaneous guided bone regeneration was necessary. The defect area was grafted with freeze-dried bone grafts (FDBG) and covered with a Healiguide

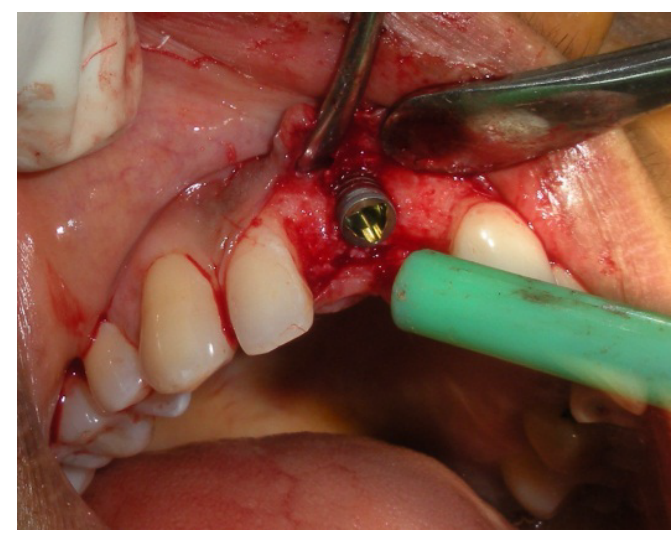

Figure 2. Exposed implant threads due to fracture of buccal cortical plate.

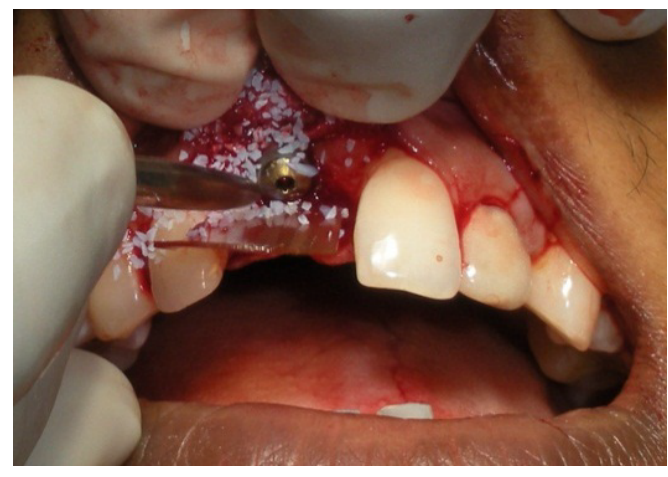

Figure 3. Placement of alloplastic bone graft material (Bio-oss).

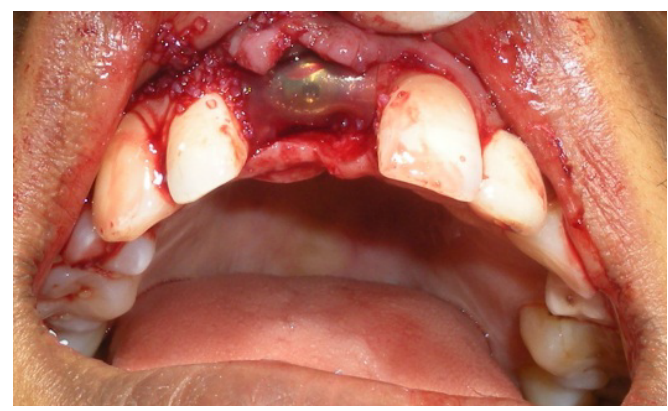

Figure 4. Placement of resorbable barrier membrane (Healiguide). 


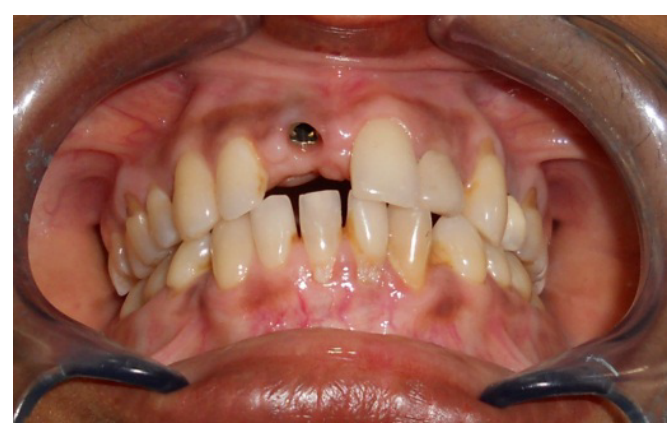

Figure 5. Gingival biotype after removing healing abutment.

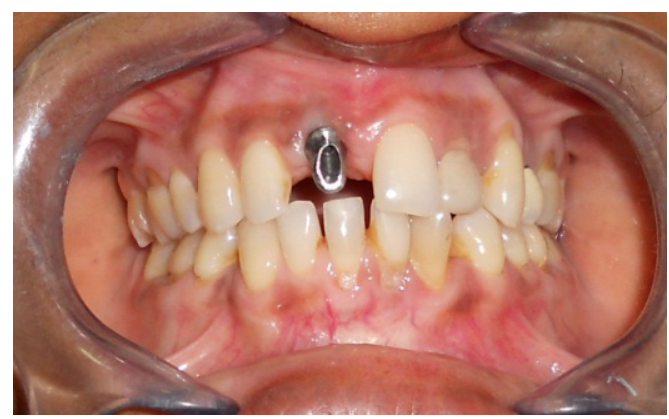

Figure 6. Modification of the esthetic abutment.

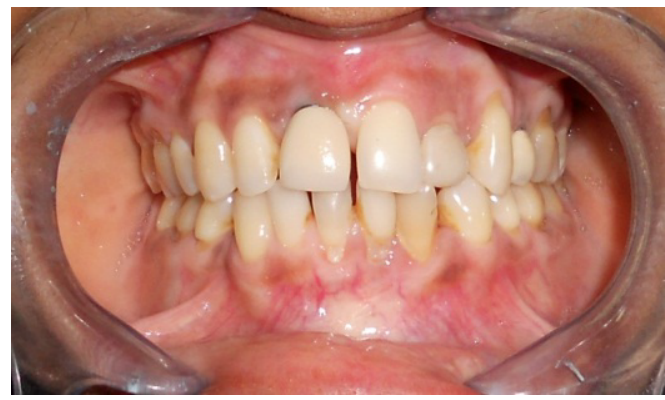

Figure 7. Intra oral view after crown cementation.

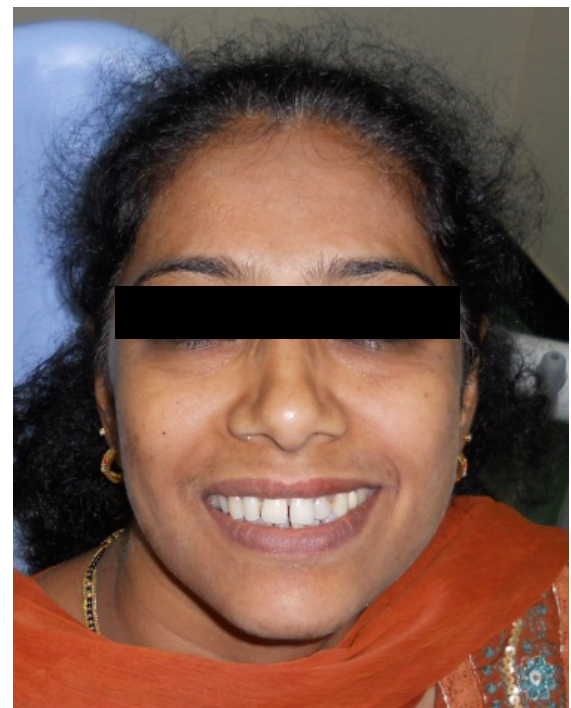

Figure 8. Extra oral view with implant restoration. barrier membrane, which was chosen in this case due to its excellent handling characteristics and a longer resorption profile (six months). It protected the graft material during regeneration. Excellent ridge width and soft tissue dimension was obtained, which provided for implant placement and restoration in the aesthetic zone with optimal results. A two-stage surgical procedure was performed with implant exposure after six months of implant placement and regeneration.

\section{Conclusion}

To maximize functional and esthetic results, implants should be placed accordingly to prosthetic needs and design. Due to bone resorption after extraction, ideal placement of implants would be often impossible without prior hard and soft tissue augmentation. Several techniques such as Guided Bone Regeneration (GBR), onlay veneer grafting, inter-positional inlay grafting, ridge splitting technique and distraction osteogenesis are available nowadays. Based on advantages and disadvantages of these techniques, solution of each case requires customization and often combination of these techniques. Thus a deep knowledge of these techniques will allow the surgeon to properly select the right combination for prosthetic needs and especially for the esthetic and function of patients.

\section{References}

1. Schropp L, Wenzel A, Kostopoulos L, Karring T (2003) Bone healing and soft tissue contour changes following single-tooth extraction: a clinical and radiographic 12-month prospective study. Inter J PerioRestor Dent 23: 313-323. [Crossref]

2. Linda G, Belser UC (2009) Implant loading protocols for the partially edentulous esthetic zone. Int J Oral Maxillofac Implants24:169-179. [Crossref]

3. Duncan JM, Westwood M (1997) Ridge widening for the thin maxilla- A clinical report. Int J Oral Maxillofac Implants 12:224-227.[Crossref]

4. Elian N, Jalbout Z, Ehrlich B, Classi A, Cho SC, et al. (2008) A two stage full arch ridge expansion technique. Review of the literature and clinical guidelines. Implant Dent 17:16-20.[Crossref]

5. Guirado JL, Yuguero MR, Carrióndel Valle MJ, Zamora GP (2005) A maxillary ridge splitting technique followed by immediate placement of implants: a case report. Implant Dent 14:14-20.[Crossref]

6. Christoph HF, Ronald EJ, Andreas F (2002)A systematic review of the survival of implants in bone sites augmented with barrier membranes in partially edentulous patients. J Clin Periodontol29:226-231.[Crossref]

7. Buser D, Brägger U, Lang NP, Nyman S (1990) Regeneration and enlargement of jaw bone using guided tissue regeneration. Clinical Oral Implants Research1: 22-32. [Crossref]

8. Dahlin C, Linde A, Gottlow J, Nyman S (1988) Healing of bone defects by guided tissue regeneration. PlastReconstrSurg81: 672-676.[Crossref]

9. Buser D, Bornstein MM, Weber HP, Grütter L, Schmid B, et al. (2008) Early implant placement with simultaneous guided bone regeneration following single tooth extraction in the esthetic zone: A cross-sectional, retrospective study in 45 patients with a 2-to 4-year follow-up. J Periodontol79: 1773-1781.[Crossref]

10. Donos N, Kostopoulos L, Tonetti M, Karring T (2005) Long-term stability of autogenous bone grafts following combined application with guided bone regeneration Clin Oral Implants Res 16:133-139.[Crossref]

11. Sandberg E, Dahlin C, Linde A (1993) Bone regeneration by the osteopromotion technique using bio-absorbable membranes: an experimental study in rats. Int J Oral MaxillofacSurg51: 1106-1114.[Crossref]

12. Urban IA, Jovanovic SA, Lozada JL (2009) Vertical ridge augmentation using guided bone regeneration (GBR) in three clinical scenarios prior to implant placement: a retrospective study of 35 patients 12 to 72 months after loading. Int J Oral Maxillofac Implants24:502-510.[Crossref]

13. Simion M, Trisi P, Piattelli A (1994) Vertical ridge augmentation using a membrane technique associated with osseointegrated implants. Int J PerioRestor Dent 14:496-511. [Crossref] 
Ahmad M (2017) Implant placement with guided bone regeneration in the maxillary aesthetic zone - A case report with 3 years of follow up

14. Retzepi M, Donos N (2010) Guided Bone Regeneration biological principle and therapeutic applications. Clin Oral Implants Res21:567-576.[Crossref]

15. Rocchietta I, Fontana F, Simion M (2008) Clinical outcomes of vertical bone augmentation to enable dental implant placement: a systematic review. J Clin
Periodontology35:203-215.[Crossref]

16. Parma-Benfenati S, Tinti C, Albrektsson T, Johansson C (1999) Histologic evaluation of guided vertical ridge augmentation around implants in humans. Int $J$ Periodontics Restorative Dent 19:424-437.[Crossref]

Copyright: (C2017 Ahmad M. This is an open-access article distributed under the terms of the Creative Commons Attribution License, which permits unrestricted use, distribution, and reproduction in any medium, provided the original author and source are credited. 